\title{
The effect of concordance-based approach on learning phrasal verbs to Iranian EFL learners
}

\author{
Nour Mohammadi, Esmaeel \\ Literature and Humanities, University of Sistan and Baluchestan, Iran (Esmaeel.nm@gmail.com) \\ Tashakori, Sakine \\ Literature and Humanities, University of Sistan and Baluchestan, Iran (Sakine.tashakori@yahoo.com)
}

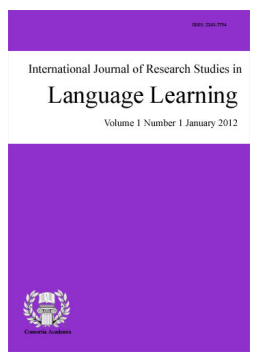

ISSN: 2243-7754 Online ISSN: 2243-7762

OPEN ACCESS

\section{Abstract}

The aim of this study was to investigate the difference between high and low proficiency learners who studied phrasal verbs by an English teaching method that uses concordance methods. In addition, the difference between the performances of high and low proficiency learners in the concordance group together and the students in the traditional group was investigated. Fifty two pre-intermediate learners from Parsian Institute participated in this study. They were divided into controlled and experimental groups based on the Oxford Placement Test. They were taught English phrasal verbs through concordance and traditional approaches during 12 sessions of instruction. Before the instruction began, they were given a list of the phrasal verbs to ensure they do not know the meaning of the phrasal verbs. Before the treatment began, they were given a pre-test. After the instruction, they were given the post-test to answer and after three weeks of the instruction, they were given a delayed-posttest to answer. Pre and post and delayed-posttests were the same with the internal reliability index of 0.78 , according to KR-21 formula. Findings showed that there was a significant difference between high and low proficiency learners using concordance concerning the acquisition of phrasal verbs, with the high proficiency learners outperforming the low one. However, there was not a significant difference between the two groups taught phrasal verbs through concordance and traditional approaches.

Keywords: corpus; concordance approach; phrasal verb; traditional approach 


\section{The effect of concordance-based approach on learning phrasal verbs to Iranian EFL learners}

\section{Introduction}

The advancement in technology leads to the emergence of lots of new ways for facilitating learning and teaching languages in order to have wider contacts with people around the world. This is the case especially in Iran in which English is taught as a foreign language. Among these are the widespread use of concordance and corpora. Using of these online materials is a new way for moving from the traditional methods of teaching to the new materials. As a result, not only more real and natural data are presented to learners, but also the instructions are presented to the learners through recent technological technique. As a result, teachers distance from the boring traditional technique they used before because the teachers played more the role of the facilitator in the classroom to get the meaning at the end after encouraging learners to guess the meaning based on the sentences. In addition, Johns (1991) and Tribble and Jones (1990) state that since concordance programs have become available to teachers for developing teaching materials, their possibilities have been seen as offering new and exciting directions for developing teaching materials, enabling students themselves to make direct discoveries about language (as cited in Celik, 2011). So, learners are encouraged to be active in the classroom and helped each other in learning English, and not just look at the teacher as the only knowledgeable person in the class. Although, all these depend on how the teachers and the learners value different methods for teaching English. Moreover, in a genre perspective, concordance is very suitable since it brings to class real patterns of language, and genre contextualization.

\section{Review of Literature}

In English there are many features of the vocabulary and grammar that seem difficult for non-native speakers of English. Phrasal verb is the very specific trait of the English language. The ability to use phrasal verbs is something intrinsic for native speakers of the English but pose a great deal of difficulty for nonnative speakers of English. In addition, since its significance has been highlighted in many books, it seems necessary to be taught by second language learners. Kawaguchi, Minegishi, and Durand (2009) in the book Corpus Analysis and Variation in Linguistic explained the reason for its significance. Among the reasons was the widespread use of phrasal verbs in the conversation and in fiction. According to them "it is difficult to define a word without the use of phrasal verbs" (p. 122). Also, phrasal verbs are common in every day formal and informal speech and writing (Hart, 2009). Therefore, learners should know how to use them appropriately in the context.

The meaning of the phrasal verbs is not always transparent. In fact, the meaning is not predictable from its part. Another difficulty lies in the form of the particle which resembles that of prepositions and hard to distinguish from one another. Also, the construction is very productive. The above mentioned difficulties in the nature of the phrasal verbs lead to the error or avoidance strategy on the part of the learners (Azzaro, 2012). Despite the significance of the phrasal verb, it has been the neglected part of language instruction. Nowadays the researchers try to manipulate different strategies to see the possible effect of them on the phrasal verbs. Previously, traditional methods were used in the teaching of phrasal verbs. The students were presented with a long list of phrasal verbs to deal with and used them in new utterances. The students had to memorize them and the teacher provided the equivalent of the phrasal verbs in the modern language for them (Laresn-Freeman, 2000).

Nowadays, technology plays an important role in all aspects of human life. Therefore, its integration in teaching and learning is worthwhile. Among all the technological features is the widespread use of computers in the classroom to present games and fun to the classroom and to present new methodological software to be used as an educational tool. The new multimedia, the internet and the various forms of distance learning are the tools 
that can be used to reinforce language learning and to help language teaching. The use of internet made it possible to search in all kinds of on-line dictionaries and to find as much authentic languages. Among them is the use of corpus-based application in the classroom. Corpora have been used in English for teaching vocabulary, grammar, collocations and conversations, etc. In addition, lots of studies have been done in order to investigate the impact of using corpora on the language teaching and learning.

Supatranont (2005) aimed at identifying the effects of the concordance-based and the conventional teaching method on engineering students' English vocabulary learning. The researcher tried to solve the problem of engineering students' insufficient vocabulary size for academic reading. The objectives of the study were to compare the concordance learning effect with the conventional teaching method's effects on the measures of definitional knowledge, transferable knowledge and vocabulary retention rates. It also tried to explore the attitudes of the learners with regard to the concordance-based approach. The population of the study consisted of 1000 engineering undergraduate students that were typically homogenous in terms of age, gender, first language, level of present education and previous English study. The participants were divided into two intact groups, the experimental and the controlled groups. The students from both groups were matched in pairs according to their vocabulary proficiency on the pretest. In the first stage before the instruction began, a list of high frequency words from the academic texts in the engineering field were chosen, and used to design all lessons, materials, activities, task and tests.

The data were gathered through the pretest, posttest and the delayed test, review tasks, teachers' field notes, students' logs, questionnaires and interviews. Regarding learning effects, the results of the data revealed that the students' average scores in the experimental group were significantly higher than those in the traditional group in all measures of definitional knowledge, transferable knowledge and retention rates with large effect sizes, especially the transferable knowledge. In terms of learning processes, findings revealed that students' concordancing and language skills improved significantly. They could acquire skills in operating the concordancer quickly whereas it took a longer time for them to master the skills in identifying various aspects of words, interpreting concordance texts and deducing word meaning from contexts. At the end of the study, these skills improved noticeably although the students could not fully master them. If the training could be extended, the students thought that they could utilize the concordance-based method for their self-study. Despite some difficulties, students expressed positive attitudes towards the method. They found the method challenging, interesting and useful for studying language.

In another study, Hedayat and Mehrgan (2012) sought to find the possible differences that may exist between the two modes of vocabulary presentation, concordancing and vocabulary teaching. For this purpose, 120 high school freshmen were selected randomly. Then 60 students were selected as homogenous based on the Nelson's pre-test vocabulary. During fifteen weeks of the instruction, one group were taught through short texts and the other one through the concordance. At the end, a vocabulary achievement test as a post-test were administered to the two groups to determine any possible variations resulting from applying two different modes of vocabulary presentation. Results showed that those students who followed a text-based approach toward the vocabulary acquisition outperformed and were more successful regarding the degree of vocabulary acquisition and retrieval than those taught through the technique of concordancing.

In addition, Fatemi (2012) aimed at identifying the types of English collocations (noun+ verb, noun +preposition, noun +noun, adjective noun) that are best learned and retained by Iranian EFL learners using concordance-based instruction. Moreover, the effect of learner's entry collocation knowledge on their learning of the abovementioned four types of collocations through concordance-based instruction in general was investigated. Besides, the learners' attitudes toward learning collocations using concordance-based instruction were evaluated. To this aim, a test of 60 multiple-choice items was designed and given to 30 sophomore English majors studying in University of Sistam and Baluchestan, as participants. The reliability of the test was estimated to be 0.74 , using the KR-21 formula. The design of the study was one group pre-test, post-test. The same test was administered to the participants as pre-test, post-test and the delayed-test. After the pre-test was administered, 
the participants were taught the four types of collocations using concordance lines in twelve thirty-minute sessions. Immediately after the twelfth session ended, the post-test was given to the participants and after about one month, the delayed post-test was administered to see the effects concordancing might have on the retention of these four types collocations. The results of the statistical analyses indicated that although concordancing was effective in learning all four types of collocations, it made no difference in the learning and retention of each type of collocations. Furthermore, it was observed that learners with higher levels of collocation knowledge benefited more from concordance-based instruction. The result of the attitude questionnaire indicated that learners generally viewed concordancing to be effective and interesting in learning different types of collocations. Therefore, the results suggest that concordance-based instruction can be very effective in learning and retaining any kind of collocation.

Agnes Huang (2010) investigated whether a corpus-based instruction could deepen EFL learners' knowledge of periphrastic causatives: make, cause, and let. The participants were 47 Taiwanese undergraduates from two intact classes. One class as the experimental group received a three-month corpus-based instruction; the other as the control group had no instruction on English causatives. A pre-test was first administered to measure participants' knowledge of periphrastic causatives. Following a data-driven model of illustration-interaction-induction, the researcher as instructor conducted the instruction and took notes on students 'performance. After the instruction, a post-test was given to both groups whereas a questionnaire on learning effects and students' feeling for corpus-based activities were distributed to the experimental group. The results indicated that the experimental group improved and outperformed the control group significantly in the post-test. The questionnaire results confirmed that the instruction was effective in increasing students' knowledge of the three causatives. However, the field notes revealed learners' difficulties in using certain causatives.

Carmen Barrera Cobos Cubism (2010) gets students to act as language researchers through the analysis of concordance listings obtained from a corpus. The main question in this study is how effective is the use of corpus linguistics in the L2 classroom. The participants in this study were native Spanish speakers learning English as a second language at an English language teaching institution. They were encouraged to analyze the data obtained, to come up with their own hypotheses about how language works and behaves and to interpret and describe the language. The results obtained in this study suggest that the use of corpus linguistics in the L2 classroom is effective, indeed. Despite the fact that the students who participated in this study had never heard of corpus linguistics before, they felt comfortable analyzing concordance listings and hypothesizing about how words behave in the language. Students understood the instructions, and analyzed the data without difficulty.

Taking phrasal verbs into account, Mohammadi and Mirdehghan (2014) investigated the efficacy of teaching phrasal verbs via CMC (computer-mediated-communication) to Iranian EFL senior high school students. For this purpose, two groups of EFL students, 40 each, aged 15 to 20, were randomly selected from a population of 300 students at Iranian senior high school. For ensuring the homogeneity of the participants, Oxford Placement Test was administered. The treatment lasted eight weeks, three sessions per week. Students in the controlled group received the instruction via the logging to the website and downloading the course materials on the phrasal verbs. The students in the controlled one received no internet feedback and just were taught the phrasal verbs in the classroom, though. The required data were collected by means of the post-test at the end of the instruction. The findings of this study indicated that the participants in the experimental group outperformed language learning program and could motivate students to have an active role in the phrasal verbs learning.

The review of related studies indicated that the investigation of concordance-based approach on teaching English phrasal verbs seems necessary since phrasal verbs are an important part of the vocabulary knowledge. Accordingly, this study is an attempt to explore the possible effects and differences between concordance and traditional approaches in teaching phrasal verbs. In addition, the difference between the performances of high and low proficiency learners who were studied Phrasal verbs by the concordance-based approach was investigated. 


\subsection{The Rational and Purpose of the Study}

Teaching English vocabulary is difficult and very important since vocabulary plays an important role in all aspects of language learning: reading, speaking, listening, and even writing. Traditionally, vocabularies were taught through giving learners a long list of vocabularies with their translations to memorize. Nowadays, the advancement in technology leads to the emergence of lots of new ways for facilitating learning and teaching languages so that they can have better access to natural and real data. One of these technological techniques is concordance. Concordance proved to be appropriate for learners with advance level of proficiency. However, no research proved it to be useful for pre-intermediate learners. Also, lots of works had been done to teach collocations, verb causative, etc. to the learners through concordance. However, none of them investigated the usefulness of this methodology for teaching phrasal verbs. As a result, in order to see if there is any significant difference between high and low proficiency learners taught phrasal verbs by concordance approach, first this study seeks to prove the difference in the performance of learners taught phrasal verbs by concordance and traditional approach and then the main question of the study is going to be answered. Based on the above objective, the following questions were posed:

$>\quad$ Is there any significant difference between the performance of Iranian EFL learners taught phrasal verbs by a concordance-based approach and that of learners taught by a traditional approach?

$>\quad$ Is there any significant difference between the performances of high and low proficiency learners taught phrasal verbs by a concordance-based approach?

\subsection{Significance of the Study}

Recently, concordancing remains largely a bottom-up, word-based activity. Corpus- based research has become increasingly popular in applied linguistics and education. The creation of the educational corpora concerns specialized areas such as textbook corpora, classroom observation corpora, learner corpora and corpora of texts with controlled vocabulary (Tono, 1988, as cited in Garcia, Flowerdew \& Aston, 1988). In the present study, it is an attempted to explore the effect of the concordance approach on the learning of the phrasal verbs in comparison to the traditional approach, a kind of controlled paper-printed concordance phrasal verbs. As result, it may pave the way for the emergence of the new ways of teaching and learning that might benefit both teachers and learners. It is hoped that the result of the current study can be employed by policy makers, curriculum designers, educational organizations, academic specialists, administrators, course developers, teachers, an at the same time learners. Also, the study might offer a successful way for teaching of the phrasal verbs in the context of Iran.

\section{Method}

\subsection{Participants}

The participants of the study were fifty two male and female learners studying English at Parsian institute in Lamerd, Fars. They were chosen based on the convenience. One-hundred eighty learners took part in the first phase of the study to answer the questions related to phrasal verbs. All the participants were native speakers of Persian with 15 to 21 range of age. Thirty two of the participants were female and the rest were male. Most of them were high school students and some were studying in the university. They were all in pre-intermediate level based on the standard set by the institute. The reason for choosing these participants among was their low knowledge of English phrasal verbs.

\subsection{Instruments}

The instruments applied in this study were: (a) Quick Placement Test Version one (as both placement and 
proficiency tests), (b) Vocabulary Knowledge Test, (c) Phrasal Verbs Test (as pre-test, post-test), (d) concordance lessons, (e) concordance and traditional exercises.

Quick Placement Test Version One - In order to make sure that all the pre-intermediate level participants were placed correctly in the experimental and controlled groups, Quick Placement Test Version one was used. In addition, this test was used as a proficiency test in order to categorize the high and low proficiency learners in the experimental group. This test was published in 2001from Oxford University Press and University of Cambridge Local Examination Syndicate. It contained 60 multiple choice questions categorized in two parts. Both parts contained questions on different aspects of language like vocabulary, grammatical features, prepositions, cloze tests. The participants had enough time to answer the questions, at least 50 minutes.

Vocabulary Knowledge Test - This test was administered at the very beginning of the experiment in order to know the initial knowledge of the participants with regard to the phrasal verbs. The learners were given eighty phrasal verbs chosen randomly from the book English Phrasal Verbs in Use by Michael McCarthy and Felicity O'Dell (2004). For each phrasal verb, one sentence was chosen from Longman Dictionary and the learners were asked to write the Persian translation of each phrasal verb. Then, forty eight phrasal verbs that have the lowest percentage of the correct answers were chosen.

Phrasal Verbs Test (as pre-test, post-test and delayed-test) - In order to test the phrasal verbs knowledge of the participants in the first session, the phrasal verbs test was administered as the pre-test, post-test and delayed-test. The researcher made test was 60 multiple choice items test on forty eight phrasal verbs that were taught. It contained four parts such as to find the meaning of the underlined phrasal verbs, to choose the correct phrasal verbs for the underlined words or phrases, to choose the phrasal verbs to complete the sentences and to choose the correct verbs to complete the sentences. In order to estimate how reliable the test was, the test had been administered to the pilot group of twenty six participants in Parsian Institute. For calculating the internal reliability of the test, the KR-21 formula was used. The reliability index for this test was considered to be an acceptable one, 0.78 .

Concordance and Traditional Lessons - Lessons used in this study were twelve lessons. In each lessons, four phrasal verbs were presented to the participants. By means of concordance lessons, the learners were provided with a hand-in concordance of the twelve sample of real use of the phrasal verbs taken from COUBUILD English Course and some other sources. In these sentences, phrasal verbs were highlighted to attract the attention of the students. By means of the traditional lessons, the learners were provided with four phrasal verbs each session. For each phrasal verb, the meaning and also two examples for each one were presented. The validity of these lessons was checked by showing them to five English professors beforehand. According to their suggestions, some changes had been done on the lessons. In addition, twenty students in pre-intermediate level checked the lessons in order to be sure the lessons were suitable for their levels.

Concordance and Traditional Exercises - The participants were provided with exercises after each lesson. In each lesson, three types of exercises were presented. In concordance exercises, for each three sentences one phrasal verb was the correct answer. The exercises were in the forms like choosing the correct phrasal verbs to complete the sentences, guessing the meaning of the underlined phrasal verbs, replacing the underlined words or phrases with the correct phrasal verbs. In traditional exercises, everything was the same as the concordance exercises except that in the concordance exercises, for each three sentences one phrasal verb was correct. However, in the traditional exercises, each sentence had one correct answer. The validity of the exercises was checked by five professors. Like the lessons, some changes had been done based on their suggestions. Also, these exercises had been checked by twenty students in pre-intermediate level in order to be sure that they are suitable according to their level.

\subsection{Data collocation procedures}

The procedure used for conducting the study was as follows. An Empirical method was used for 
investigating the research hypotheses. The data collection procedures for this study took place at Parsian Institute in Lamerd, Fars in 2012 during three months. Four intact groups were used in order to see the effectiveness of teaching phrasal verbs through concordance approach vs. traditional approach. According to the standards set by Parsian Institute, all the subjects were at the pre-intermediate level. In order to be sure that the subjects were placed correctly in these four groups, Oxford Placement Test Version One was administered at the very early beginning. In addition, this test was used to understand the proficiency level of the subjects in experimental group. In another words, the subjects in the experimental groups were categorized in the high and low proficiency learners by means of administrating Oxford Placement Test Version One. Before the instruction started, subjects were provided with eighty phrasal verbs in which for each of these phrasal verbs one sentence was written. They were asked to write the Persian translation of the phrasal verbs. Then, forty eight phrasal verbs that had the lowest percentage of correct answers were chosen. In that way, the researcher was sure that the participants didn't know the meaning of the phrasal verbs.

As mentioned above, all of subjects were at the pre-intermediate level of proficiency according to the standards set by the institute. The reason for choosing this proficiency level was that the concordance was proved to be suitable for the teaching of collocations and vocabulary at high level of English proficiency. However, it wasn't proved to be appropriate for the learners at pre-intermediate level. So, the researcher preferred to select pre-intermediate level. Forty eight phrasal verbs chosen randomly from English Phrasal Verbs in Use (2004) were chosen to be taught to the participants. The reasons for choosing these forty eight phrasal verbs were as follows. First, the subjects were not much familiar with the phrasal verbs and most of the participants taught that the phrasal verbs had the same meaning as their component. In addition, they were appropriate for their age and their level of proficiency. Finally, none of the subjects were familiar with these phrasal verbs. The subjects were told that their grades in the exams were kept confidential.

The instruction began by the pre-test. The participants were given enough time to answer to sixty multiple choice items divided into four parts. The session after the pre-test, the researcher started to teach to four groups. Two groups were taught through traditional approach and two other groups were taught through concordance approach. Forty eight phrasal verbs were taught in twelve sessions, each session four phrasal verbs. Each session lasted forty five minutes. These phrasal verbs were presented to the controlled groups through the traditional approach. The participants were provided with a table of four phrasal verbs in each session. The meaning of each phrasal verb and two examples for each one were given in front of it. The researcher (the only conductor of this study) read these phrasal verbs one by one and wrote them on the board. The teacher read that phrasal verbs aloud for the learners to repeat and drill. Then, she provided the subjects with the target meanings and the translations, synonyms and antonyms of these phrasal verbs. The participants then made new sentences with these phrasal verbs and did the exercises to which they were provided each session to make certain that they had completely understood the new phrasal verbs. At last, they needed to memorize the definition to be studied for the post-test.

The experimental groups were taught through the concordance-based approach. By means of concordance, the learners were provided with the table of the sample of the real use of the phrasal verbs taken from COUBUILD English Course and some other sources. While the hand-in concordance was given out among the learners, the researcher attracted the subjects' attentions to the highlighted phrasal verbs in each table. Before the teacher started to elaborate the phrasal verbs, she and learners together discussed the use and the problems of learning phrasal verbs. Then, the teacher elaborated and helped the learners to notice the features of the phrasal verbs in the sentences. The teacher encouraged them to be sensitive to the patterns of the language. The participants were divided into small groups so that they can exchange their findings together and build a bigger picture in their minds. Then, the teacher elicited the meaning of each phrasal verb from the learners and if it was the correct answer, the teacher confirmed it and wrote the target meaning of the phrasal verb on the boards. Otherwise, the teacher provided the learners with more examples and if they could not guess, the teacher herself provided the learners with the meaning. The instruction were followed by some exercises to be sure that the participants had fully learned the new phrasal verbs. 
After each four sessions, one session was held to review the phrasal verbs. The meanings of the previously taught phrasal verbs were reviewed and the participants were provided with some exercises to be done. At the end of the course, the post-test was administered to see the effects of the concordance and traditional approaches to learning phrasal verbs. Pre and post-test were the same. Three weeks after the instruction, the same test were administered again to see if the learners still knew the phrasal verbs or not. In fact, the retention of the instruction was the question. Finally, the data were submitted to Statistical Package for Social Sciences (SPSS) to see whether the results were significant or not.

\subsection{Data Analysis}

The data were submitted to Statistical Package for Social Science (SPSS) to be analyzed. The purposes of this study were as follows. First, it was to investigate the performances of Iranian learners taught phrasal verbs by the concordance-based approach and that of learners taught by the traditional approach. Second, the study was to examine if there is any significant difference between the performances of high and low proficiency learners taught phrasal verbs by a concordance approach. In order to answer the first question, after calculating the descriptive statistics for both pre and post-test, independent-sample t-test was used after the means of gain scores for both the experimental and controlled groups were calculated. To see if there is any significant difference between the performances of high and low proficiency learners in teaching of the concordance methodology, the study applied independent-sample t-test to compare the means of the gain scores for high and low proficiency learners' groups. It is important to mention that this study was done only for the recognition of the meaning of the phrasal verbs. Meanwhile, all the statistical analyses were performed in the environment of the SPSS software version 21 and the alpha level (level of the study) was set at 0.05 .

\section{Results}

\subsection{The Homogeneity of the Four Groups}

At the early beginning of the instruction, Oxford Placement Test Version One was administered in order to place subjects correctly into the experimental and controlled groups. The scores obtained from this exam were submitted to the SPSS software and Following Descriptive Statistics were the results.

\section{Table 1}

Descriptive Statistics for the Placement Test of Concordance and Traditional Approaches

\begin{tabular}{lccc}
\hline \multicolumn{1}{c}{ Groups Placement } & $n$ & $M$ & $S D$ \\
\hline Concordance & 26 & 23.4231 & 8.43883 \\
Traditional & 26 & 22.8077 & 6.80011 \\
\hline
\end{tabular}

As the Table 1 indicated, the mean and SD (Standard Deviation) were 23.42 and 8.43 for the concordance groups with 26 participants, respectively. In addition, the mean for the traditional groups with 26 participants was 22.80 and the SD was 6.80 .

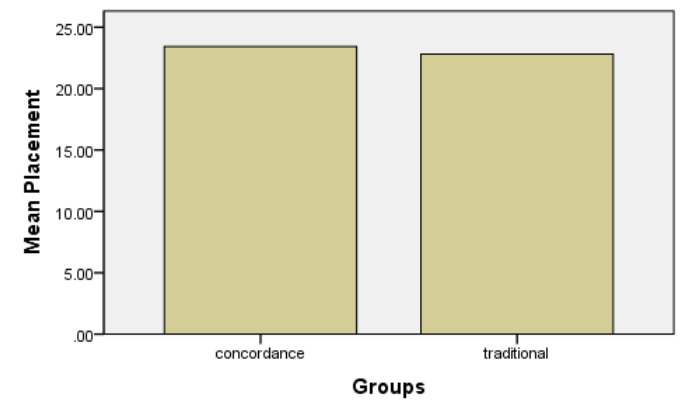

Figure 1. Concordance groups' scores mean vs. traditional groups scores mean 
The effect of concordance-based approach on learning phrasal verbs to Iranian EFL learners

As the bar graph displays above, the difference between the groups was quite small. However, to assess the significant difference that might be between groups, it is necessary to conduct further statistical analysis. In this case, an independent-sample t-test was done.

Table 2

Independent-sample T-test for the Placement Test of Concordance and Traditional Approaches

\begin{tabular}{lcccccc}
\hline \multicolumn{1}{c}{ Gain Scores } & $F$ & $P$ & $T$ & $d f$ & $p$ & $M D$ \\
\hline $\begin{array}{l}\text { Equal Variances } \\
\text { Assumed }\end{array}$ & .179 & .659 & .290 & 50 & .773 & .61538 \\
$\begin{array}{l}\text { Equal Variances Not } \\
\text { Assumed }\end{array}$ & & & .290 & 47.838 & .773 & .61538 \\
\hline $\begin{array}{l}\text { Note. } M D \text { indicates Mean Difference } \\
\end{array}$ & & & & &
\end{tabular}

As the Table 2 displays, the p. value is 0.77 . As this value is above the cut-point 0.05 , there is not a statistically significant difference in the means of the scores for the concordance groups $(\mathrm{M}=23.42, \mathrm{SD}=8.43)$ and the traditional groups $(\mathrm{M}=23.80, \mathrm{SD}=6.80 ; \mathrm{t}(50)=0.29, p=0.77)$. Therefore, concordance and traditional groups were homogeneous.

\subsection{Research Hypothesis 1}

$H_{0}$ 1: There is no statistically significant difference in the performance of Iranian Learners taught phrasal verbs by a concordance-based approach and that of learners taught by a traditional approach. The result of the descriptive statistics and the t-test will be presented below.

Descriptive Statistics - As it was mentioned previously, for testing the first null hypothesis, the mean of the gain scores for both the controlled and experimental groups were calculated. Gain scores were the subtraction of the pre-test scores from the post-test scores. In the following table, the detailed analysis of the data and the descriptive statistics are presented.

\section{Table 3}

Descriptive Statistics for the Concordance and Traditional Groups' Gain Scores

\begin{tabular}{lccc}
\hline Methods Q1 Gain Scores & $n$ & $M$ & $S D$ \\
\hline Concordance & 26 & 10.4231 & 8.45777 \\
Traditional & 26 & 8.8462 & 7.46025 \\
\hline
\end{tabular}

As given in table 3, in concordance groups with 26 participants, the mean score was 10.42 and the SD was 8.45 and for the traditional group, the scores were 8.84 and 7.46 for the mean and the SD, respectively.

Independent Samples t-test - To make sure whether there is or there is not a statistically significant difference in the means of the gain scores for the concordance and traditional groups, an independent samples t-test was run. The table 4 presents the results of the independent- samples t-test.

\section{Table 4}

Independent-samples T-test for the Concordance Groups' Gain Scores vs Traditional Groups' Gain Scores

\begin{tabular}{lcccccc}
\multicolumn{1}{c}{ Gain Scores } & $F$ & $P$ & $T$ & $d f$ & $p$ & $M D$ \\
\hline $\begin{array}{l}\text { Equal Variances } \\
\text { Assumed }\end{array}$ & .347 & .558 & .713 & 50 & .479 & 1.5769 \\
$\begin{array}{l}\text { Equal Variances Not } \\
\text { Assumed }\end{array}$ & & & & & \\
Note: MD indicates Mean Difference & & .713 & 49.233 & .479 & 1.5769 \\
\hline
\end{tabular}

According to the above table, there is no significant difference between the controlled and the experimental groups because $\mathrm{t}(50)=0.713, p=0.47$. As a result, the table indicates that there is not a statistically significant difference between the method for teaching phrasal verbs to the concordance groups $(\mathrm{M}=10.42, \mathrm{SD}=8.42)$ and 
Nour Mohammadi, E., \& Tashakori, S.

that of traditional $(\mathrm{M}=8.84, \mathrm{SD}=7.46)$.

\subsection{Research Hypothesis 2}

$H_{0}$ 2: There is no statistically significant difference between the performances of high and low proficiency learners taught phrasal verbs by a concordance-based approach.

Table 5 and 6 show the descriptive statistics and the independent-samples t-test for this research hypothesis.

Descriptive Statistics - The performances of the high and low proficiency learners in the concordance groups are shown in the following table. These are the means for the gain scores calculated by subtracting the pre-test from the post-test.

\section{Table 5}

Descriptive Statistics for the High and Low Proficiency Learners in the Experimental Groups

\begin{tabular}{lccc}
\hline High \& Low Gain Scores & $n$ & $M$ & $S D$ \\
\hline High & 12 & 14.4167 & 5.74390 \\
Low & 11 & 8.0000 & 2.44206 \\
\hline
\end{tabular}

As it can be seen in the above table, the mean score was 14.41 and the SD was 5.74 for the high proficiency learners, and for the low proficiency learners in this group, the mean was 8.00 and SD was 8.09. It seems as if there was a difference in the means for the high and the low proficiency learners.

Independent Samples t-test - The independent-samples t-test for the third null hypothesis is presented in the following table. It is provided to check the confirmation or the rejection of the null hypothesis.

\section{Table 6}

Independent-samples t-test: the high proficiency learners' gain scores vs. the low proficiency learners' gain scores in the experimental group

\begin{tabular}{lcccccc}
\hline \multicolumn{1}{c}{ Gain Scores } & $F$ & $P$ & $T$ & $d f$ & $p$ & $M D$ \\
\hline Equal Variances Assumed & 2.102 & .162 & 2.207 & 21 & .039 & 6.41667 \\
Equal Variances Not Assumed & & & 2.174 & 17.889 & .043 & 6.41667 \\
\hline
\end{tabular}

In the table 6 , the $p$ value is .03 which is less than .05. As a result, the significant difference in the mean scores of high and low proficiency learners in the experimental groups was proved. There was a significant difference in the high proficiency learners' scores $(M=14.41, \mathrm{SD}=5.74)$ and the low proficiency learners' scores $(\mathrm{M}=8.06, \mathrm{SD}=8.09 ; \mathrm{t}(21)=2.20, p=0.03$. In fact, the high proficiency learners performed better in learning English phrasal verbs based on concordance-based approach. So, the third null hypothesis was rejected.

\section{Discussion}

The purpose of the current study was to see if there is any significant difference between the performance of Iranian learners taught phrasal verbs by a concordance approach and the traditional one. Also, this question was investigated on the basis of the performance of high and low proficiency learners who were taught through the concordance-based approach. The results showed that the participants' performance in the traditional and the concordance groups did not show any significant difference. However, the finding of the present study was significant for the second null hypothesis; with high proficiency learners outperformed the low ones. The findings of the present study is compatible with the results of Fatemi's (2010) study which aimed at identifying the types of English collocations that are best learned and retained by Iranian EFL learners using concordance-based instruction. The analysis of pre-test and post-test results showed no significant difference in the learning of each type of collocation. However, the result of this study was not in line with Carmen Barrera Cubism (2012) study who tried to see how effective the use of corpus listing in the L2 classroom is. They were 
given a concordance list to analyzed, interpret, and described. The results showed that this methodology was significant and the learners felt comfortable analyzing concordance listing.

Also, the findings of this study do not support Agnes Huang's (2010) study who investigated whether a corpus-based instruction could deepen EFL learners' knowledge of periphrastic causative: make, cause, and let. The analysis of their data revealed that the experimental group improved and outperformed the control group significantly in the posttest. There might be some reasons for the first study's results. One reason might relate to the new teaching method used in the classroom. Because the learners are not much familiar with the concordance methodology, it takes time to respond positively to this technique. Maybe if the study is repeated again, the concordance methodology seems to be better than the traditional one. In addition, since in this methodology learners are presented with a large number of real and authentic data for one single word (in here phrasal verb), it may be to some extent boring for them to make direct discoveries about language themselves. Also, concordance a method needs cooperation among participants in the classroom. In fact, the concordance needs students' involvement and it promotes the friendly competitions in the classroom. Therefore, the result of this study may be due to the lack of participation and cooperation among the learners in the classroom.

The findings of the present study is compatible with the results of Fatemi's (2010) study which aimed at identifying the types of English collocations that are best learned and retained by Iranian EFL learners using concordance-based instruction and the difference between the performance of high and low proficiency learners taught through the concordance approach. The analysis of pre-test and post-test results showed that learners with higher levels of collocation knowledge benefited more from concordance-based instruction. There might be some reasons with regard to the present study. High proficiency learners may be more motivated to learn the new phrasal verbs and maybe they are more active in the classroom. As a result, they respond more positively to the concordance-based approach. In addition, each learner has different methods for learning the language. The high proficiency learners might have the learning strategy like the concordance method. As a result, their performance is better than the performance of the low proficiency learners. In addition, according to Azzaro (2012, p.5), phrasal verbs have always been difficult for non-native speakers and are often the target for error or avoidance strategies. This Azzaro's sentence may be another reason for the result of concordance methodology regarding the performance of the low ones. In another word, because phrasal verbs are difficult for non-native speakers of English, they avoid to use them. So, these phrasal verbs do not stick in mind for a long time.

\section{Implication of the Study}

Implications of this study, both the theoretical and the pedagogical, are presented below.

\subsection{Theoretical Implication}

The advancement in technology leads to the emergence of lots of new ways for facilitating learning and teaching languages in order to have wider contacts with people around the world. This is the case especially in Iran in which English is taught as a foreign language. Among these are the widespread use of concordance and corpora. Using of these online materials is a new way for moving from the traditional methods of teaching to the new one. So that, not only more real and natural data are presented to the learners, but also the instructions are presented to the learners through recent technological technique. As a result, teachers distance from the boring traditional technique they used before because the teachers played the role of the facilitators more in the classroom to get the meaning at the end after encouraging learners to guess the meaning based on the sentences. In addition, learners are encouraged to be active in the classroom and helped each other in learning English, and not just look at the teacher at the only knowledgeable person in the class. Although, all these depend on how the teachers and the learners value different methods for teaching English.

Although there was no significant difference in the performance of the learners who were taught phrasal verbs through concordance and traditional approaches and its retention, it can't be ignored that the participants 
taught phrasal verbs through the concordance approach found it more interesting and useful than the traditional methods for vocabulary learning. They believed that it can be a way for not only learning new vocabulary by practicing its usage mainly in real data, but also this is a suitable technique for learning new vocabulary and at the same time revised the previous one. Also, learning and reviewing grammatical features can be highlighted at the same time.

\subsection{Pedagogical Implications}

The findings of this research can have several implications for language teachers, course developers and learners.

$>$ As the language teachers, they can use this method for teaching vocabulary in the classroom. By using concordance, they themselves have a large number of real examples to present to their students, and they can be a real facilitator in the classroom.

$>$ As the course developers, they can use this technique to improve not only the curriculum, but also the methodology of the vocabulary learning.

$>$ As the learners, they can use this technique out of the classroom to improve their knowledge of learning English vocabulary. Because by doing so, they have an access to the wider ranges of real and authentic data and can enjoy learning English by up to date techniques specially the online one.

\section{Conclusion}

The current study was an effort to find out the effect of teaching English phrasal verbs through concordance and traditional approach. Additionally, it was designed to explore which of the high and low proficiency learners outperformed another one in the concordance methodology. For this purpose, 60 multiple choice questions were used as a pre-test and a post-test. The results of the study showed that there was not any significant difference in teaching English phrasal verbs based on concordance and traditional methods. However, the results of this study indicated that there was a significant difference between the high and low proficiency learners, with the high proficiency learners outperformed the low ones.

\section{References}

Agnes Huang, L. (2012). The effectiveness of a corpus-based instruction in deepening EFL learner's knowledge of periphrastic causative. TESOL Journal, 6, 83-108.

Azzaro, G. (2012). Phrasal verbs through data driven learning. Journal of Theories and Research in Education, 7 , $1-27$.

Carmen Barrera Cobos Cubism, M. (2010). The use of corpus linguistics to teach cognates to Spanish- speaking English language Learners. MEXTESOL Journal, 34(2), 1-22.

Celik, Sh. (2011). Developing collocational competence through web based concordance activities.

Navitas-Royal (Research on Youth and Language), 5(2), 273-286.

Chambers Dictionary of Phrasal Verbs. (2004). India: Allied Chambers.

Cowie, P. A., \& Mackin, R. (1975). Oxford dictionary of current idiomatic English. Hong Kong: Oxford University Press.

Fatemi, A. N. (2012). The effect of concordance-based instruction on Iranian EFL learner's learning of different types of collocations. Unpublished Master Thesis. Sistan and Baluchestan University, Zahedan, Iran.

Frankenberg-Garcia, A., Flowerdew, L., \& Aston, G. (Eds.). (1988). New trends in corpora and language learning. London: Continuum International Publishing Group.

Hedayat, M., \& Mehrgan, K. (2012). Concordancing vs, textual vocabulary acquisition. Advances in English Linguistics, I(1), 12-19.

Hart, C. W. (2009). The ultimate phrasal verb book ( $2^{\text {nd }}$ ed.). New York: Library of congress. 
Kawaguchi, Y., Minegishi, M., \& Durand, J. (Eds.). (2009). Corpus analysis and variation in linguistics. Netherland: John Benjamins Publishing Company. http://dx.doi.org/10.1075/tufs.1

Larsen-Freeman, D. (2000). Technique and principles in language teaching. United Kingdom: Oxford University Press.

Mohammadi, E., \& Mirdehghan, S. S. (2014). A CMC approach to teaching phrasal verbs to Iranian EFL senior high school students: the case of blended learning. Procedia Social and Behavioral Sciences, 98, 1174-1178. http://dx.doi.org/10.1016/j.sbspro.2014.03.531

McArthur, T., \& Atkins, B. (1974). Dictionary of English phrasal verbs and their idioms. Great Britain: Collins Clear-Type Press.

McCarthy, M., \& O’Dell, F. (2004). English phrasal verbs in use. London: Cambridge University Press.

Supartranont, P. (2005). A composition of the effects of the concordance-based and the conventional teaching methods on engineering student's English vocabulary learning. Unpublished doctoral dissertation, Chulangkorn University.

Whiteford, C. H., \& Dixson, R. J. (1973). American idioms and idiomatic usage. US: Regents Publishing Company. 
Nour Mohammadi, E., \& Tashakori, S. 